\title{
Effects of genistein on insect haemocytes
}

\author{
Josef Berger $^{1}$, Sylvia Walczysko ${ }^{2}$, Jitka Pávková ${ }^{2}$, Herwig O. Gutzeit ${ }^{3}$ \\ ${ }^{1}$ Faculty of Health and Social Studies South Bohemian University in České Budějovice, Czech Republic \\ ${ }^{2}$ Faculty of Biology South Bohemian University in České Budějovice, Czech Republic \\ ${ }^{3}$ Institute of Zoology Technical University in Dresden, Germany
}

\begin{abstract}
Summary
We evaluate the possibility of using insects as a haematological biomodel and we test phytoestrogen isoflavanoid, genistein, in Schistocerca gregaria, Periplaneta americana and Dysdercus cingulatus. Various reactions of haemocytes were found in these three species, both stimulation and inhibition of haemocyte concentration. The observed data reflected well the possible effects of soy products described in published studies on human subjects and it seems that future studies on the sensitivity of insect haemocytes could lead to an alternative haematological biomodel.
\end{abstract}

Keywords: alternative biomodel - haemocyte - genistein - pre-clinical prediction

\section{INTRODUCTION}

There are two reasons for safe compound tests on invertebrates: (i) evaluation of xenobiotics, which could kill these animals in nature (pesticides etc.) and (ii) the use of invertebrates as biomodels before a natural or synthesized chemical is pre-clinically tested on mammals or human volunteers. Although mammals, mainly rats, mice, dogs, rabbits and monkeys seem to be necessary for pre-clinical tests, economical, ethical, juridical and political aspects represent limiting factors for their use (Berger 2000).

The further argument for the use of invertebrate models should be that genistein, the subject of our test, binds to the estrogen receptor (the data on insect steroid receptors are not available) and inhibits protein kinases and topoisomerase and other enzymes. Hence there are numerous targets (several are mentioned below; Rickard et al. 2003, Lee et al. 2003 etc.). Insects could help to unravel the relevance of the targets for biological functions and give some information that can be further tested in vertebrates.

The crucial signalling pathways in development and some cellular and endocrine control processes have been remarkably conserved in the Animal
Kingdom. As a result, invertebrate model systems, in particular Drosophila and C. elegans, have been used extensively to unravel the molecular control of vertebrate differentiation processes. Furthermore, these and other invertebrates have proven to be extremely useful in the identification of molecular targets for pharmaceuticals of interest.

Mammalian models are both morphologically and physiologically similar to the human body. Questions concerning the precision of predictions for humans from studies on invertebrates can arise and are difficult to answer. Considerable experience with safety tests on bacteria, such as the Ames test of mutagenicity (cf. Mortelmans and Zeiger 2000), shows that predictability can be high if such a test is not general but concentrated on the defined aim. We hope that so-called alternative models on insects could incorporate some economical advantage if we gain greater experience in order to learn something of the limitations on their use in the future.

Genistein is a major soy isoflavone that acts as an estrogen agonist (cf. Rickard et al. 2003). It binds to the oestrogen receptor, with greatest affinity to receptor b. It was suggested that this compound has an important role in the development, maturation and function of a wide variety of reproductive and non-reproductive tissues (Belcher and Zsarnovsky 2001, Albertazzi 2002). Genistein 
influences different cells in a different manner through tyrosine phosphorylation or the control NADPH oxidase-associated reactive oxygen species production mediated by tyrosine kinase inhibition (Charalambidis et al. 1995, Lee et al. 2003), and membrane protection (Zavodnik et al. 2000, Bobrowska-Hagerstand et al. 2001); it inhibits superoxide production (Hwang et al. 2003), induces programmed cell death (Po et al. 2002), thymic and immune changes (Yellayi et al. 2002), and spermatogenesis (Scholz and Gutzeit 2001, Song and Gutzeit 2003b).

Genistein is protective against several chronic and degenerative diseases such as cancer, cardiovascular diseases, stroke, cataracts, brain and immune dysfunctional states (cf. Horvathova et al. 2001). This isoflavone produces effects in multiple oestrogen-sensitive tissues, e.g. abnormal cellular maturation in the vagina - included vacuolation and mucinification of the vaginal epithelium, a deficit of sperm etc. (Delclos et al. 2001, Okazaki et al. 2002). Genistein stimulates protein synthesis in osteoblasts and prevents bone loss caused by oestrogen deficiency (Albertazzi 2002).

Genistein is a selective oestrogen receptor modulator in normal and malignant uterine tissue (Diel et al. 2001). It inhibits a subset of IL-3/GMCSF-mediated signals resulted in the abrogation of DNA synthesis (Kinoshita et al. 1995). Soy, and more specifically genistein, is a dietary component that may help to explain the dramatic disparity in breast cancer risk between Asians and Caucasians (Bouker and Hilakivi-Clarke 2000). Epidemiological data supports the prostatic cancer protective effects of genistein (cf. Castle and Thrasher 2002). It has been reported that genistein can decrease prostatespecific antigen (Ghafar et al. 2002). It reduces the mean number of cancer foci per colon (Steele et al. 1995). It is conceivable that anti-cancer effects are mediated by its property of being the protein kinase inhibitor to the membrane-associated anti-apoptotic CD19-UYN complexes.

It was shown that genistein has very low toxicological risk; since it can only cause alterations in serum lipids, bone metabolism, and possibly casmition in higher doses (cf. Fitzpatrick 2003). Iodine deficiency greatly increases its antithyroid effects, whereas iodine supplementation is protective (Doerge and Sheehen 2002). Genistein has mutagenic effects on mouse lymphoma and erythropoietic cells (Misra et al. 2002) but this characteristic can be the other side of the shield, i.e. the above-mentioned anti-neoplastic effects.

As genistein effects were tested on several systems except haematological characteristics, which are essential among safety tests (Berger 1987), we assessed its effects on haemocyte morphology.

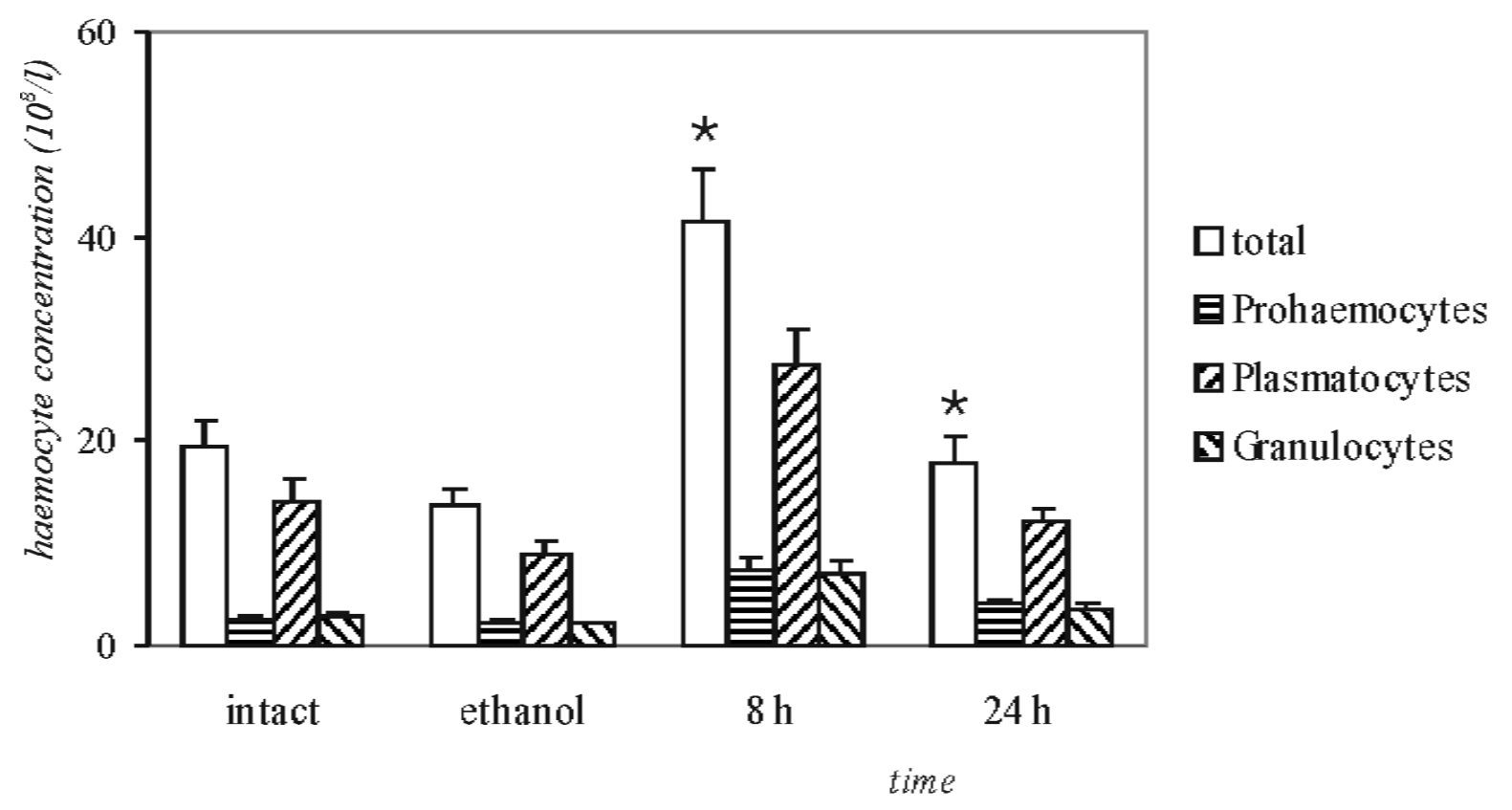

Fig. 1. Single genistein administration to Periplaneta americana; * statistically significant versus ethanol administration 


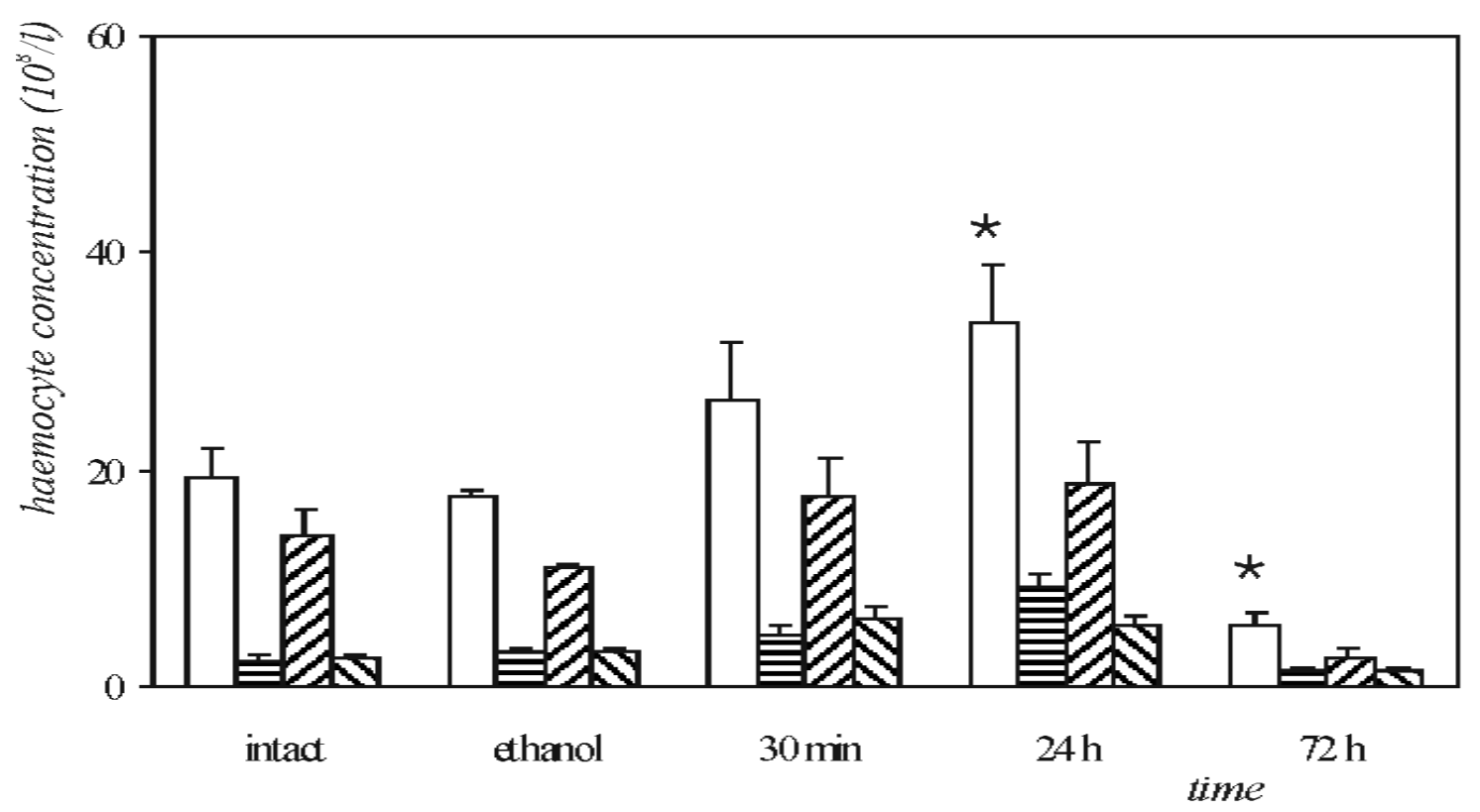

Fig. 2. Sub-chronic administration of genistein to Periplaneta americana; symbols as in Fig. 1

\section{MATERIAL AND METHODS}

We used adult Schistocerca gregaria, Dysdercus cingulatus (both from the Institute of Entomology in České Budějovice) and Periplaneta americana (from the ZOO in Prague), which were under constant temperature of $30{ }^{\circ} \mathrm{C}$ (D. cingulatus under $25^{\circ} \mathrm{C}$ ), light/dark regime $12 \mathrm{~h} / 12 \mathrm{~h}$ (D. cingulatus under regime $16 \mathrm{~h} / 8 \mathrm{~h})$. Usual diets and water were available ad libitum. We examined at least six animals at each time point.
Haemolymph was taken after cutting of $1 \mathrm{~mm}$ of antennae (D. cingulatus, P. americana) or leg (S. gregaria, D. cingulatus) or after inserting the iliac membrane (S. gregaria). The total haemocyte count was estimated using the Bürker chamber and Türk solution. Blood smears were stained panoptically with overnight incubation in ethanol and then in May-Grünwald solution for $6 \mathrm{~min}$ and Giemsa-Romanowski one (1:3, solution:water) for $45 \mathrm{~min}$ and haemocytes were differentiated from at least 100 cells/animal.

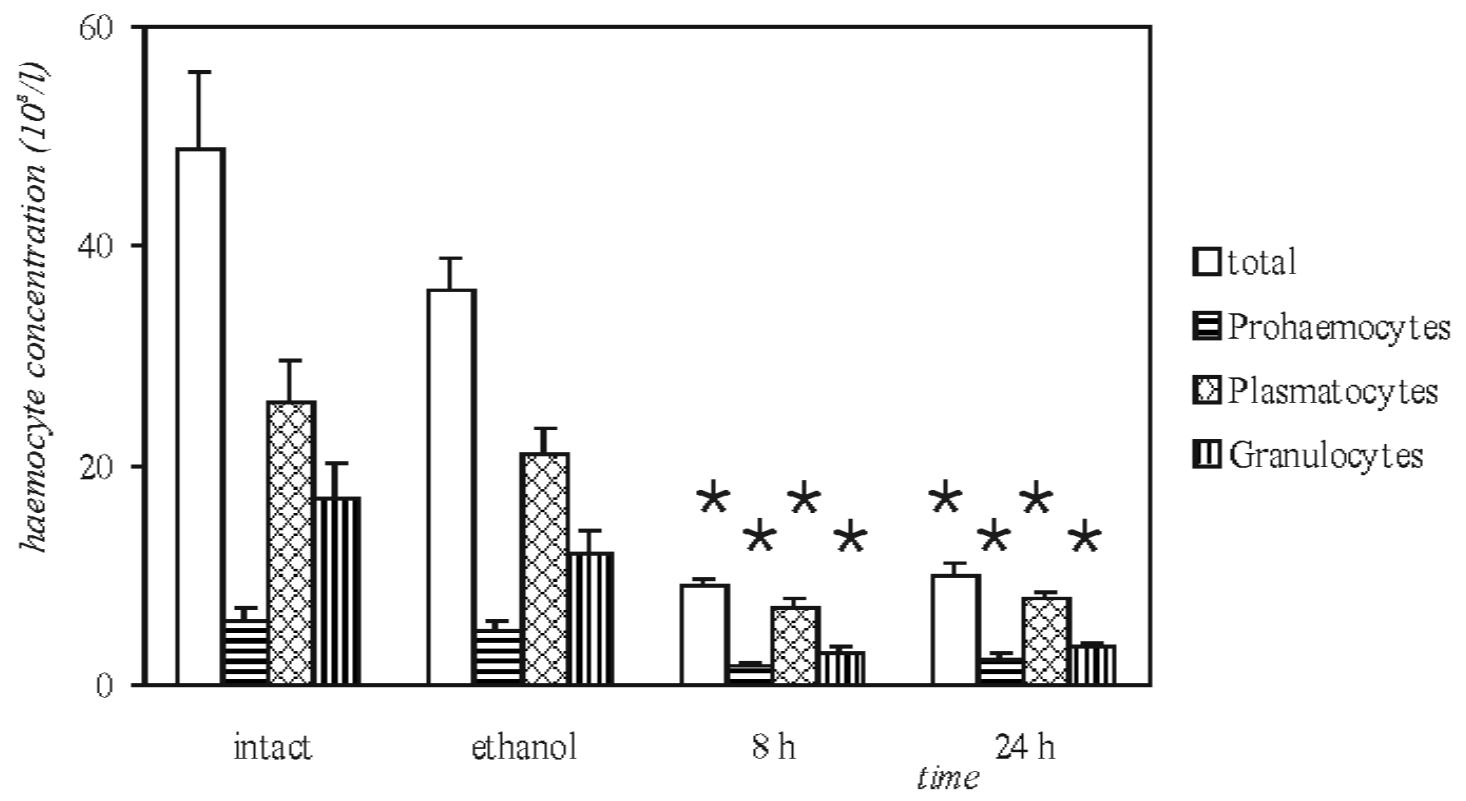

Fig. 3. The influence of single genistein on haemocytes of Schistocerca gregaria; * significant versus ethanol administration 
$100 \mathrm{mmol} / \mathrm{l}$ of genistein in ethanol was administered s.c. in the dose $5 \mathrm{~m} /$ animal (S. gregaria, behind pronotum), $2.5 \mathrm{~m}$ /animal (P. americana, under blade on the abdomen) or $2 \mathrm{~m} /$ animal (D. cingulatus, under blade on the abdomen); these volumes were in the ratio to the animal size. Genistein was administered as a single dose or sub-chronically for seven consecutive days, that is one genistein application each day.

Results are expressed as mean \pm s.e.m. The two sided Mann-Whitney $U$ test at the significance level $2 \mathrm{a}=0.05$ was used.

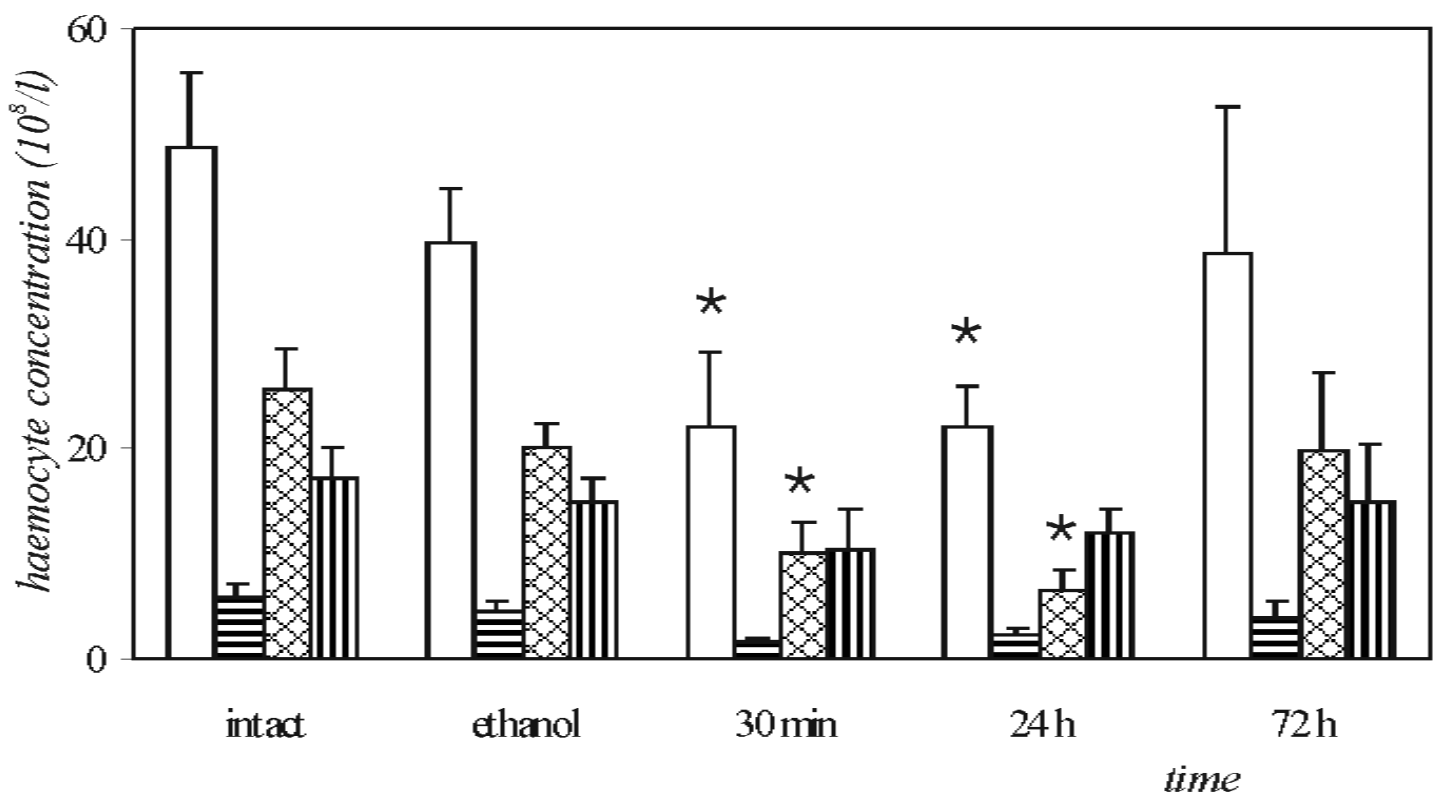

Fig. 4. The influence of sub-chronic genistein on haemocytes of Schistocerca gregaria; symbols as in Fig. 3

\section{RESULTS AND DISCUSSION}

The total haemocyte number following a single genistein application to P. americana is documented in Fig. 1. illustrating that ethanol s.c. and handling did not significantly influence this characteristic, but the genistein induced an increase of haemocyte concentration. The increase of haemocyte numbers persisted for $24 \mathrm{hrs}$ after treatment of the animals, but the fall is significant versus the value observed at $24 \mathrm{~h}$. No changes in the differential count were observed.

Similar findings were found in P. americana after sub-chronic treatment: an estimation of the total haemocyte count only 30 mins after genistein application was not elevated significantly while this number was significantly decreased 3 days after the last compound application (Fig. 2). The relative number of prohaemocytes slightly increased in contrast to the equivalent very slight decrease in the proportion of plasmatocytes and granulocytes. Similar oscillations were observed in haematology studies carried on mammals (Berger 1980) where stimulation of blood cell increase resulted in a consequent decrease caused by the previous depletion of the possibility of cell multiplication. Thus, we suggest that genistein can stimulate the haemocyte number in P. americana.

In contrast, the total haemocyte count in S. gregaria was significantly suppressed after both single or sub-chronic genistein administration (Fig. 3 and 4). Only minor changes were observed in the proportion of individual types of haemocytes, and absolute counts of haemocyte type, therefore, mimic the total haemocyte count (Fig. 3 and 4). A single dose of the tested compound induced a slightly significant increase in the total haemocyte count 72 hrs after treatment in D. cingulatus (Fig. 5). No significant changes of this characteristic were observed in sub-chronically treated animals (Fig. 6), 
while the proportion of prohaemocytes increased significantly following both single or sub-chronic treatment.

Thus, we have documented three different reactions in three different insect species following genistein administration. As haemocytes play an important role in insects, analogous to mammalian blood cells, it is likely that we have described an alternation in the immune system. Our preliminary data (unpublished results) indicate a decrease of nucleolar coefficient not only in suppressed haemocytes of S. gregaria but also in haemocytes of P. americana after sub-chronical genistein administration. Such results were observed even in the time points when we have found increased numbers of these cells. Therefore, we can favour the data of O'Connor et al. (2002) and Yellayi's group (2003) which found that genistein induced suppression of immunity.

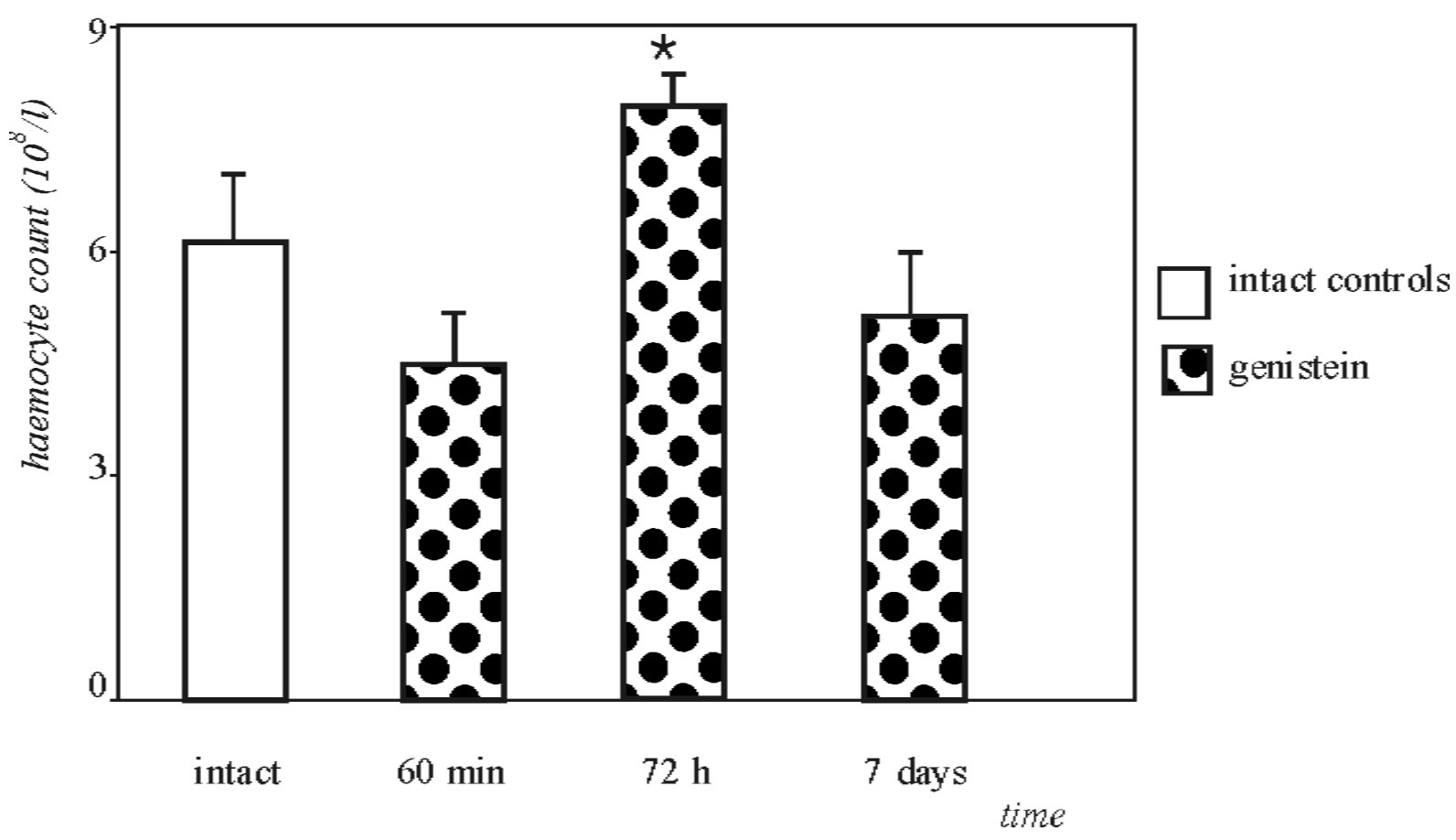

Fig. 5. Effects of a single dose of genistein on total haemocyte counts in Dysdercus cingulatus; * significant versus intact controls

Findings of other authors (reviewed by Yellayi et al. 2003) indicate a higher risk of allergy, reduced titers of antibodies, and morbid upper respiratory infections in human subjects fed soy-formula. Genistein can, therefore, suppress immunity and high soy intake may bring a risk of health injury.

Are our results and the above mentioned published results in contradiction to the observed benefit of soy diet for prevention of prostate cancer (Ghafar et al. 2002), cardiovascular and many other (Horvathova et al. 2001) diseases? Our finding of the genistein-induced stimulation of the total haemocyte count in P. americana seems to be in keeping with observations of Seike et al. (2003) who document that genistein has the potential to promote rat lung carcinogenesis possibly via the stimulation of cell proliferation and DNA changes caused by oxygen radicals, but we should first characterise the insect system in more detail before talking about predictability in this area: we suppose that genistein could rather mimic an ecdysteroid-like effect. With respect to proliferation, the stimulation could be analysed further by BrdU incorporation using flow cytometry as it was carried out with primary testis cultures (Song and Gutzeit 2003a, b). Genistein cancerogenity in common dietary concentration is, moreover, very improbable with respect to its anti-mutagenicity (Park et al. 2003), epidemiologically documented benefit (Horvathova et al. 2001, Castle and Thrasher 2002) and many other published data. Another hypothesis for the observed increase in haemocyte number could be that genistein is a trigger for lowered cell aggregation (cf. Gottstein et al. 2003) which makes available a higher concentration of haemocytes which are normally deposited in tissues. 
The findings presented of different reactions in three selected insect species are in agreement with previous data on mammals, including humans, but the molecular mechanisms of genistein-induced changes are too poorly understood to exactly interpret the observed data.

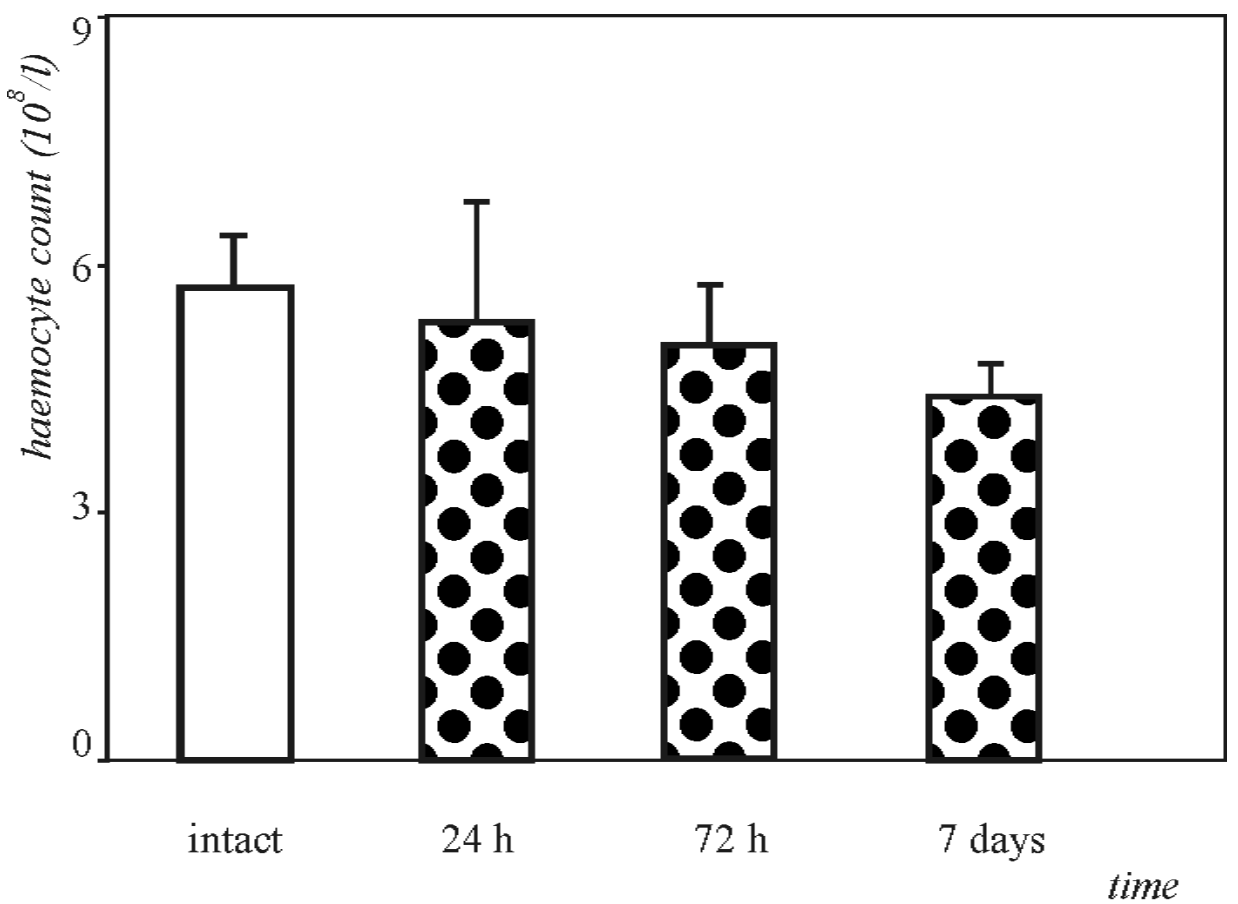

Fig. 6. Effects of a sub-chronic genistein administration on total haemocyte counts in Dysdercus cingulatus

\section{ACKNOWLEDGEMENTS}

This work was supported by grants no. 1259/02 and 1894/03 (to J.B.) from the Ministry of Education of the Czech Republic.

Received $16^{\text {th }}$ June 2003.

Published online $10^{\text {th }}$ July 2003.

\section{REFERENCES}

Albertazzi P.: Purified phytoestrogens in postmenopausal bone health: is there a role for genistein? Climacteric 5: 190-196, 2002.

Belcher S.M. and A. Zsarnovszky: Estrogenic actions in the brain: estrogen, phytoestrogens, and rapid intracellular signaling mechanisms. J. Pharmacol. Exp. Ther. 299: 408-414, 2001.

Berger J.: Leucokinetic study. Morphology of the bone marrow and blood after experimental induction of marrow hypoplasia by cyclophosphamide in laboratory rats. Folia Haematol. 107: 862-877, 1980

Berger J.: Haematological preclinical recording of adverse drug reactions - current status, problems, and needs. Part I: Standardization of experiments in relation to haematological examination. Folia Haematol. 114: 1-15, 1987.

Berger J.: Social and ethical issues in exploratory research of biomodels (In Czech). Kontakt 2: 144-150, 2000.

Bouker K.B. and L. Hilakivi-Clarke: Genistein: does it prevent or promote breast cancer? Environ. Health Perspect. 108: 701-708, 2000.

Bobrowska-Hagerstand M., A. Wrobel, B. Rychlik, G. Bartosz, T. Soderstrom, Y. Shirataki, N. Motohashi, J. Molnar, K. Michalak, H. Hagerstrand: Monitoring of MRP-like activity in human erythrocytes: inhibitory effect of isoflavpnes. Blood Cells Mol. Dis. 27: 894-900, 2001.

Castle E.P. and J.B. Thrasher: The role of soy phytoestrogens in prostate cancer. Urol. Clin. North Am. 29: 71-81, 2002.

Charalambidis N.D., C.G. Zervas, M. Lambropoulou, P.G. Katsoris, V.J. 
Marmaras: Lipopolysaccharide-stimulated exocytosis of nonself recognition protein from insect hemocytes depend on protein tyrosine phosphorylation. Eur. J. Cell Biol. 67: 32-41, 1995.

Delclos K.B., T.J. Bucci, L.G.Lomax, J.R.Latendresse, A. Warbritton, C.C. Weis, R.R.Newbold : Effects of dietary genistein exposure during development on male and female CD (Sprague-Dawley) rats. Reprod. Toxicol. 15 : 647-663, 2001.

Doerge D.R. and D.M. Sheehen: Goitrogenic and estrogenic activity of soy isoflavones. Environ. Health Perspect. 110, Suppl 3: 349-353, 2002.

Diel P., K. Smolnikar, T. Schulz, U. LaudenbachLeschowski, H. Michna, G. Vollmer: Phytoestrogens and carcinogenesis-differential effects of genistein in experimental models of normal and malignant rat endometrium. Hum Reprod. 16: 997-1006, 2001.

Fitzpatrick L.A.: Soy isoflavones: hope or hype? Maturitas 44: S21-S29, 2003

Ghafar M.A., E. Golliday, J. Bingham, N.M.Mansukhani, A.G. Anasatasiadis, A.E. Katz: Regression of prostate cancer following administration of Genistein Combined Polyccharide (GCP), a nutritional supplement: a case report. J. Alterm. Complement. Med. 8: 493-497, 2002.

Gottstein N., B.A. Ewins, C. Eccleston, G.P. Hubbard, I.C. Kavanagh, A.M. Minihane, P.D. Weinberg, G. Rimbach: Effect of genistein and daidzein on platelet aggregation and monocyte and endothelial function. Br. J. Nutr. 89: 607-16, 2003.

Hwang J., J. Wang, P. Morazzoni, H.N. Hodis, A. Sevanian: The phytoestrogen equol increases nitric oxide availability by inhibiting superoxide production: an antioxidant mechanism for cellmediated LDL modification. Free Radic. Biol. Med. 34: 1271-1282, 2003.

Horvathova K., A. Vachalkova, L. Novotny: Flavonoids as chemoprotective agents in civilization diseases. Neoplasma. 48: 435-441, 2001.

Kinoshita T., T. Yokota, K. Arai, A. Miyajima: Suppression of apoptotic death in hematopoietic cells by signaling through the IL3/GM-CSF receptors. EMBO J. 14: 266-275, 1995.

Lee V.M., P.A. Quinn, S.C. Jennings, L.L. Ng: NADPH oxidase activity in preeclampsia with immortalized lymphoblasts used as models. Hypertension 41: 925-931, 2003.

Misra R.R., S.D. Hursting, S.N. Perkins, N. Sathyamoorthy, J.C.Mirsalis, E.S.Riccio, J.A.Crowell: Genotoxicity and carcinogenicity studies of soy isoflavones. Int. J. Toxicol.21: 277-285, 2002.
Mortelmans K. and E. Zeiger: The Ames Salmonella/microsome mutagenicity assay. Mutat. Res. 455: 29-60, 2000.

Okazaki K., S. Okazaki, H. Nakamura, Y. Kitamura, K. Hatayama, S. Wakabayashi, T. Tsuda, T. Katsumata, A. Hishikawa, M. Hirose: A repeated 28-day oral dose toxicity study of genistein in rats, based on the 'Enhanced OECD Test Guidline $407^{\prime}$ for screening endocrinediscrupting chemicals. Arch. Toxicol. 76 : 553559, 2002

Park K.Y., K.O. Jung KO, S.H. Rhee, Y.H. Choi: Antimutagenic effects of doenjang (Korean fermented soypaste) and its active compounds. Mutat Res. 523-524:43-53, 2003.

Po L.S., T.T. Wang, Z.Y. Chen, L.K. Leung: Genistein-induced apoptosis in MCF-7 cells involves changes in $\mathrm{Bak}$ and $\mathrm{Bcl}-\mathrm{x}$ without evidence of anti-oestrogenic effects. Br. J. Nutr. 88: 463-469, 2002.

Rickard D.J., D.G. Monroe, T.J. Ruesink, S. Khosla, B.L. Riggs, T.C. Spelsberg: Phytoestrogen genistein acts as an estrogen agonist on human osteoblastic cells through estrogen receptors alpha and beta. J. Cell Biochem. 89: 633-646, 2003.

Scholz S and H.O. Gutzeit: Lasting effects of xenoand phytoestrogens on sex differentiation and reproduction of fish. Environ. Sci. 8:57-73, 2001.

Seike N., H. Wanibuchi, K. Morimura, M. Weil, T. Nishikawa, K, K. Hirata, J. Yoshikawa, S. Fukushima: Enhancement of lung carcinogenesis by nonylphenol and genistein in a F344 rat multiorgan carcinogenesis model. Canver Lett. 192: 25-36, 2003.

Song M. and H. O. Gutzeit: Effect of 17- $\alpha-$ ethynyloestradiol on germ germ cell proliferation in organ and primary culture of medaka (Oryzias latipes) testis. Develop. Growth Differ., in press, 2003a.

Song M. and H. O. Gutzeit: Primary culture of medaka (Oryzias latipes) testis: a test system for the analysis of cell proliferation and differentiation. Cell Tissue Res. (in press) $2003 b$

Steele V.E., M.A. Pereira, C.C. Sigman, G.J. Kelloff: Cancer chemoprevention agent development strategies for genistein. J. Nutr. 125, Suppl. 3: 713S-716S, 1995.

Yellayi S., A. Naaz, M.A. Szewczykowski, T. Sato, J.A. Woods, J.Chang, M.Segre, C.D. Allred, W.G.Helferich, P.S.Cooke: The phytoestrogen genistein induces thymic and immune changes: A human health concern? Proc.Nat. Acad. Sci. U.S.A. 99: 7616-7621, 2002.

Yellayi S., A. Naaz, M. A. Szewczykowski, T. Sato, J.A. Woods, J. Chang, M. Segre, C.D. Allred, 


\section{Berger et al.}

W.G.Helfrich, P.S. Cooke: The phytoestrogen genistein suppresses cell-mediate immunity in mice. J. Endocrinol. 176: 267-274, 2003.

Zavodnik L.B., I.B. Zavodnik, E.A.Lapshina,

A.P. Shkodlich, M. Gyszewska, V.U. Buko:
Hypochlorus acid-induced lysis of human erythrocytes. Inhibition of cellular damage by the isoflavonoid genistein-8-C-glucoside. Biochemistry 65: 946-951, 2000.

\section{* Address:}

Josef Berger, Department of Preclinical Studies, Faculty of Health and Social Care, South Bohemian University, Branišovská 31, 37005 České Budějovice, Czech Republic; berger@jcu.cz 